\title{
Enhancing Teachers' Intercultural Competence with Online Technology as Cognitive Tools: A Literature Review
}

\author{
Qinxu Jiang ${ }^{1}$, Shimin Soon ${ }^{2} \&$ Yuandong $\mathrm{Li}^{3}$ \\ ${ }^{1}$ School of Anesthesiology, Xuzhou Medical University, Jiangsu, China \\ ${ }^{2}$ School of Public Health, University of Hong Kong, Hong Kong, China \\ ${ }^{3}$ Department of Human Resources, Xuzhou Medical University, Jiangsu, China \\ Correspondence: Yuandong Li, Department of Human Resources, Xuzhou Medical University, Jiangsu, China.
}

Received: December 24, 2020

Accepted: February 3, 2021

Online Published: February 8, 2021

doi: $10.5539 /$ elt.v14n3p1

URL: https://doi.org/10.5539/elt.v14n3p1

\begin{abstract}
In an increasingly interconnected world, intercultural competency has become an essential skill for many. It is important for students to learn this skill, but are teachers equipped to instil such knowledge not just adequately, but also objectively and without prejudice? In light of the recent explosion in telecommunications-assisted teaching and learning, this is a timely review on the use of online technology as cognitive tools for enhancing teachers' intercultural competency skills. Though various online platforms for learning and sharing have been developed for and used by students over the years, less attention has been given to teachers' needs; only five well-documented projects pertaining to the upskilling of intercultural competence were found. We focus on these five projects and draw from them best practices, platforms and methods of potential and other insights, which would provide the best benefits in meeting the professional development needs of teachers.
\end{abstract}

Keywords: ICC, intercultural competence, technology, professional development, online learning

\section{Introduction}

The world is becoming more and more interconnected as individuals of different cultural backgrounds come into contact more frequently, be it for business, studies, work, or leisure (Deardoff, 2009). Against this backdrop of globalisation, teachers face many new challenges in coping with cultural diversity in a multicultural classroom (Hajisoteriou, Karousiou, \& Angelides, 2018). This may be more commonly seen "in societies with diverse populations and in societies where there are regular influxes of immigrants into the schools" (Villegas-Reimers, 2003 , p. 40). For instance, in countries where students are taught English as a foreign or second language (EFL/ESL), English-language teachers feel not only the need to teach their students English linguistic knowledge and skills but also instill intercultural skills, to help their students better master communication skills and improve interactions with people of other languages and cultures (Fungchomchoei \& Kardkarnklai, 2016; Mede \& Cansever, 2017).

The understanding of multiculturalism is no longer limited to the domain of language teaching and learning, and has expanded to encompass a broader scope such as international education and multicultural teaching and learning, which have permeated multiple disciplines in varied contexts and now encompasses elementary, secondary and post-secondary education levels (Schlein, 2018). For instance, international faculty - which play a prominent role in teaching, research, services, and globalisation to the United States of America's (U.S.A.) higher education institutions with their own cultures and world perspectives - are a growing population on U.S.A. campuses (Lee \& Lim, 2017). Consequently, it would behoove academic faculty members to be sufficiently competent to teach a heterogeneous group of both domestic and international students in a culturally diverse environment (which involves a wide range of perspectives, knowledge, insights and experiences) due to the growing mobility of international students into Western universities (Manzoor, 2016). Furthermore, besides popular study destinations in Western countries, other emerging countries in Asia such as China are starting to attract more international students, adding to campus and classroom cultural diversity. Internationalisation of education has led to increased teaching faculty, allowing them to provide education on a transnational and cross-cultural level through online learning platforms (or in-person by flying in) to engage in teaching activities at international branch campuses, give seminars or intensive sessions of block teaching in collaborative 
institutions (Sia, 2014; Smith, 2009).

In the midst of all these developments, teachers obviously play a very important role in being knowledge imparters. However, less attention is given to the fact that teachers are lifelong learners as well. Teacher professional development (TPD) - defined as "a long-term process that includes regular opportunities and experiences planned systematically to promote growth and development in their profession" by Villegas-Reimers (2003, p. 12) - is considered a vital aspect of teachers' professionalism and self-growth. The rationale of TPD lies in the fact that teachers' perceptions, teaching practice and beliefs have a significant impact on students' learning experiences and outcome (McCalman, 2014; Villegas-Reimers, 2003) and on the success of educational reform (Villegas-Reimers, 2003). Multiculturalism and internationalisation of education necessitates interculturally prepared and competent teachers for better engagement in dynamic teaching and research activities, so that their students may develop a higher level of ICC (Deardoff, 2009; Polat \& Ogay, 2014). "Teaching, learning, and culture are interconnected" (Schlein, 2018, p. 50); ICC development in the current age of rapid globalisation should become one integral and compelling dimension of TPD (Davis, Cho, \& Hagenson, 2005).

The use of technology as a tool to train teachers' intercultural competency (ICC) is an emerging field of great interest with vast potential, and the existing literature, albeit limited, offers insight into how technology as cognitive tools helps develop teachers' ICC. In particular, we note that, notwithstanding the emergence of Asian countries as international learning destinations, research in this field has thus far been conducted mostly in European countries and U.S.A., likely attributable to early adoption of technology combined with a multicultural environment created by the high levels of the movement of people, such as the migration and arrival of international students. Nevertheless, the literature reveals that in the past two decades, technology has evolved to address intercultural issues in the education field - sometimes directly, and sometimes indirectly. One such medium is online platforms - teachers can use them to investigate multi- and inter-cultural issues, as a virtual gathering space to share relevant knowledge and experiences, or exchange ideas to improve their teaching practices. This is essentially an informal approach to knowledge sharing through online social networking, i.e. the technological community of practice (Hew \& Hara, 2007). Community of Practice (CoP) refers to "groups of people who share a concern, a set of problems, or a passion about a topic, and who deepen their knowledge and expertise in this area by interacting and ongoing basis" (Hew \& Hara, 2007, p. 4). In this sense, teachers who engage in this virtual community have shared interests pertaining to the practice of intercultural teaching and learning.

This article aims to investigate how technology as cognitive tools can contribute to teachers' ICC training and learning. We first give a definition of ICC, illustrating the importance and urgency of promoting teachers' ICC. Next, we review and discuss how different models of online interaction and exchange have been employed in teacher education to facilitate teachers' ICC development. Thereafter, we explore the nature of online learning of ICC and problematic issues which have emerged in relation to this activity. This article concludes by outlining implications for policy and future research directions in developing teachers' ICC.

\section{Literature Review}

The concept of ICC, according to Deardoff (2009), is defined as "a person's ability to interact effectively and appropriately in cross-cultural situations based on his or her intercultural attitudes, knowledge and comprehension and skills" (Gopal, 2011, p. 374). To develop this ability, one has to grasp three central components of (1) attitudes, (2) knowledge and comprehension, and (3) skills (Deardoff, 2009), which are defined as follows:

(1) Attitudes refer to holding an open outlook towards other cultures and respecting and valuing them, being intrinsically motivated to learn, and avoiding ethnocentric assumption of one's own culture (Gopal, 2011).

(2) Knowledge and comprehension pertain to having an understanding of gender roles in intercultural settings, acquiring in-depth understanding of the target language (including verbal and nonverbal cues), and developing cultural self-awareness such as understanding how one's own culture influences one's identity, behaviours, values and way of thinking (Gopal, 2011).

(3) Skills relate to experimenting with meaning, being critical of one's communication with others for meta-cognitive knowledge, having communication skills, and self-reflection of noticing, coding, interpreting (Gopal, 2011). 


\subsection{The Importance of Enhancing Teachers' ICC}

The importance of enhancing teachers' ICC can be understood from two perspectives: the needs of the students, and the teachers. Global awareness or international mindedness, the ability to communicate with individuals from backgrounds of differing cultures, religions, and ethnicities in the global arena, and the development of critical thinking are acknowledged as important dimensions of the 21 st century skills for a student (Fungchomchoei \& Kardkarnklai, 2016; McCalman, 2014; McCloskey, 2012). In other words, students are expected to develop global citizenship (Habib, 2018) in the ever-increasingly multicultural world.

In a multicultural educational setting, educators are required to develop a curriculum that is "culturally sensitive, culturally responsive, and culturally relevant" (Dejaeghere \& Cao, 2009, p. 437; Schlein, 2018, p. 48). However, such a curriculum would become feasible only when instructors are equipped with intercultural knowledge and skills and are better able to reflect upon their pre-existing biases, discrimination, stereotypes about diversity (Hajisoteriou et al., 2018) or ethnocentrism. Teachers' ICC is linked not only to recognition of cultural diversity, but also to their emotional aspect, appreciation of closeness and respect towards students and their families (Gutiérrez Esteban et al., 2015).

For ESL/EFL learners, Fungchomchoei and Kardkarnklai (2016) note that - beyond merely picking up English linguistic knowledge and skills - ESL/EFL learners want to communicate effectively with others during intercultural encounters outside classrooms. For international students, who bring in experiences and perspectives from diverse cultures, Ryan and Hellmundt (2003) record that they wish for their lecturers to respect and understand their cultures, and treat them in a socially just way. Doing otherwise leads to them feeling undervalued and marginalised, which can be detrimental to their studies - or even to a university's global reputation (Ryan \& Hellmundt, 2003). International students also need to develop their own ICC for their future career advancement, especially those who wish to work in international companies or organisations (Manzoor, 2016).

Promoting ICC has significant implications for teachers as well. A classroom is not a culture-neutral zone cultural expectations are exercised on an instinctive, subconscious level, and neither students nor teachers are free from this (Copur-Gencturk, 2019). This is an issue, for culture creates biases. In a classroom, if teachers fail to recognise the cultural assumptions they bring into the classroom or what their own implicit biases are, they may inadvertently accord privilege and/or marginalise particular cultural groups or nationalities, be they individuals or even entire groups (Dervin, 2014). Consequently, their actions could potentially result in stereotyping and stigmatisation of the said individuals and/or groups, both within and beyond the classroom setting (Dervin, 2014). Arthur and Brown (2017) found that international students were more inclined to engage in academic misconduct (such as plagiarism) due to personal, cultural, and situational variables. However, Poyrazli and Isaiah (2018) noted that international students' grades had improved significantly with the presence of international faculty, or when they were under the care of professors who reached out more, or utilised a more interactive teaching style, or had approachable and outgoing personalities.

We may intuit that international faculty - who could come from the same or a similar background - might offer a sense of grounding and solidarity to the international students and address their concerns (or inappropriate behaviour) more deftly by virtue of this, especially if the international faculty member has attained understanding of the host country's educational traditions and rules. Alternatively, local faculty with high levels of intercultural knowledge, interpersonal skills, or emotional intelligence (EQ) could also be well-placed to handle such matters. To this end, the infusion of intercultural content into classroom teachings is a strategy potentially leading to higher awareness of cultural differences and biases, and in turn, self-moderation of implicit bias in both students and teachers. More effective communication and better rapport between the two parties is likely to be achieved, creating a positive impact on students' academic performance and learning.

\subsection{The Urgency of Teacher ICC Training and Learning}

Despite rising awareness of the need to improve teachers' ICC, literature has identified that teachers appear to be under-prepared to teach in a multicultural context (Hajisoteriou et al., 2018). Deardoff's (2009) findings show that worldwide, teachers have minimal or inadequate ICC knowledge or skills; some are even unreceptive to the attainment of ICC knowledge and skills. Polat and Ogay (2014) compared pre-service teachers' ICC level by surveying between 84 teachers from Switzerland and 101 teachers from Turkey. Results showed that the ICC levels of both groups of pre-service teachers were average. Notwithstanding this, pre-service teachers from Switzerland had higher ICC than their Turkish counterparts. This difference was likely attributable to the fact that Swiss preservice teachers received pertinent training through multiculturalism and intercultural education courses, while such courses were unavailable in Turkey (Polat \& Ogay, 2014). This study illustrates that training 
does make a difference for teachers' ICC development. This is worth bearing in mind when one learns that Marta Garrote and María Fernández's study (2016) on pre-service ESL teachers revealed that the majority of the European teachers only had an average level of ICC, underscoring the need to promote teachers' ICC training to a higher level for more effective teaching in practice. In a Chinese context, Lei (2021) surveyed 201 pre-service ESL teachers at a normal university to investigate their ICC and discovered that their ICC level was only moderate. The results also showed that female teachers had higher ICC than their male counterparts, but there was no association between the ICC levels and the teachers' family backgrounds (i.e. if they were of urban or rural family origins).

In-service language teachers also face similar issues. Fungchomchoei and Kardkarnklai (2016) found that ESL Thai teachers at four secondary schools seemed to lack clear perception of ICC and effective approaches, and were thus unable to effectively interweave cultural knowledge relevant to the language in question into their class teachings, despite their desire to do so. Their study findings suggested the necessity of further training of in-service teachers (Fungchomchoei \& Kardkarnklai, 2016). In China, Han and Song (2011) investigated teacher cognition of ICC among Chinese English-language teachers at a northeastern Chinese university through a questionnaire survey. Their findings revealed that the university's English-language teachers' conceptions of ICC and its relationship with English language teaching was ambiguous, even though they perceived it to be important and strongly wished to develop students' ICC (Han \& Song, 2012). The results also showed that the teachers lacked cultural knowledge pertaining to the language they were teaching, a reflection of the suboptimal ICC-related content within their own training materials (Han \& Song, 2012). Put together, all of the above findings make it clear that implementation of ICC to teachers' education is most certainly an indispensable global requirement.

Outside the language-class setting, in his qualitative study of higher education faculty members in Pakistani universities, Habib (2018) noted most of his participants had limited understanding of the two notions of "international mindedness and ICC" (p. 60) and seemed to hold an attitude which favored the teaching and learning of local cultures over international perspectives in their pedagogies and classes. Based on his study findings, Habib (2018) called for professional training to help teachers develop a global mindset and be prepared to instill it to their students. In Lee and Lim's (2017) review of international faculty working in higher education, they found that - when compared with domestic faculty - a high proportion of international faculty expressed more dissatisfaction with their jobs due to issues and challenges facing them including but not limited to linguistic barriers, cultural barriers, social isolation, employment visa, tenure and promotions. Of particular concern are culture barriers; similar to the international students' acculturating experiences, international faculty may well feel stressed and discouraged when they feel they are not competent enough to tackle classroom situations arising from cultural or academic assessment differences. This is the consequence of having no or insufficient prior training about culture and institutional differences due to the inherent expectations that the staff would pick up these skills while on the job (Lee \& Lim, 2017). Cultural barrier issues can also lead to homesickness, loneliness, and perceived isolation by their colleagues (Lee \& Lim, 2017).

Conversely, domestic faculty in higher education face comparable challenges in teaching international students. For example, Ryan and Hellmundt (2003) point out that in Australia, where higher education universities host a large body of international students, many lecturers recognise the growing diversity of the student body. However, they felt ill-prepared and unequipped to teach these students with respect to curriculum, pedagogy and assessment (Ryan \& Hellmundt, 2003). On the other side of the coin, the international students perceived themselves as unappreciated and opined that their learning needs were not adequately met (Ryan \& Hellmundt, 2003). Studies on domestic faculty's teaching experience with international students in other emerging host countries are scarce, but in one rare study in China, Jiang, Yuen and Horta (2020) discovered that international students were dissatisfied with Chinese lecturers' teaching style/methodology, and materials provided. More specifically, some issues highlighted were too much rote learning, simply reading off PowerPoint slides, authoritative teaching styles, and outdated textbooks that were incongruent with international students' familiarity with (and expectations of) more interactive classes where critical thinking skills were applied. Such perspectives imply that some Chinese teachers may have insufficient ICC awareness or competence training competence training in pedagogy, curriculum or communication with international students.

Studies on transnational teaching have further highlighted intercultural issues facing teachers. Smith (2009) notes that many faculty members are not adequately trained before embarking on transnational teaching in a new environment. Hoare (2013) conducted an ethnographic case study on the experiences of a group of Australian teachers who were involved in a transnational education (TEN) program with mature students in Singapore. Findings revealed that these transnational educators had encountered many cultural barriers in intercultural 
teaching, and experienced anxiety and ethnocentric tendencies due to unsupported acculturation. Fortunately, they were able to engage in self-reflection and transform their teaching practices, which helped further increase their human capital by improving their teaching capabilities both at home and abroad. Hoare (2013) advocated that universities should undertake interventions to help advance the development of ICC for their transnational educators, so that they are well prepared for transnational teaching experiences. Gopal (2011) points out that teachers who receive training of ICC outperform those who have little intercultural exposure with more prowess and tenacity; this means that the effect of ICC in transnational teaching cannot be ignored. To date, this aspect receives little recognition, even in established host countries. Nawaz (2018) investigated transnational teaching strategies by analyzing a United Kingdom's (UK) post-1992 university's documents of internationalisation strategy, annual reports, staff training and development programs etc. for the period between 1999 and 2016, and interviewing 11 stakeholders consisting academic staff member, educational developers and professionals services staff members. His study found that the faculty members at the university lacked the knowledge and skills needed for effective pedagogical teaching, and there was less interest at the university or faculty level in ensuring that faculty members received appropriate training before departing for international teaching assignments (Nawaz, 2018).

Students' learning needs, and the necessity of mastering 21 st century competencies, demand that their teachers be concomitantly ready to deal with these in addition to other societal and educational challenges (Dejaeghere \& Cao, 2009). It is regrettable that at present, teachers' intercultural knowledge, skills and attitudes have yet to catch up to the extent that they are able to meet these needs and challenges (Dejaeghere \& Cao, 2009).

Since current standards are unsatisfactory, it is imperative to empower teachers by helping them develop ICC corresponding to their multicultural educational responsibilities and effective teaching requirements (Dejaeghere \& Cao, 2009). Technology crossing spatial and temporal constraints borne on traditional training methods of workshops or seminars is a pragmatic and valuable tool if used appropriately (White-Clark, Robertson, \& Lovett, 2017).

\section{Methodology}

Due to the relatively novel nature and narrow focus of the topic of interest, a search was performed on electronic databases and Google Scholar, with no constraints on the date of publication so that more suitable matches could be found. The keywords used for the searches are as follows: "cultural competence", "multiculturalism", "multicultural education", "professional development", "international education", "intercultural competence", "intercultural competency", "intercultural learning", "intercultural teaching", "international relations", "innovation" and "technology". The articles were then reviewed individually to determine if:

1) they pertained to projects with an online element

2) they said projects were aimed at fostering teacher's ICC

\section{Results}

In line with the literature research strategy described above, a total of five articles met the inclusion criteria and were qualified for this literature review. The following table shows a summary of the pertinent characteristics of the five projects in the articles which qualified for use: 
Table 1. Summary of studies that have involved the use of technology as cognitive tools

\begin{tabular}{|c|c|c|c|}
\hline Author & Year & Study participants & Title of online project \\
\hline Ferdig et al. & 2007 & $\begin{array}{l}185 \text { pre-service teachers took part in the } \\
\text { RCE project. They were doctoral } \\
\text { candidates from: } \\
\text { - Iowa State University (US lead), UF, } \\
\text { University of Virginia, } \\
\text { - Institution of Education in the } \\
\text { University of London (European lead), } \\
\text { Aalborg } \\
\text { - University in Denmark, and } \\
\text { University of Barcelona in Spain. }\end{array}$ & $\begin{array}{l}\text { - } \text { Reading Classroom Explorer (RCE) } \\
\text { - International Leadership in } \\
\text { Educational Technology funded by Europe } \\
\text { and the U.S.A }\end{array}$ \\
\hline Carroll, Britton, \& Barr & 2010 & $\begin{array}{l}\text { Teachers from five European countries - } \\
\text { including the UK, Poland, Netherland, } \\
\text { Italy and Finland. }\end{array}$ & $\begin{array}{l}\text { The Continuing Intercultural Professional } \\
\text { Development in Europe (CIPDE) project. }\end{array}$ \\
\hline Hajisoteriou et al. & 2018 & $\begin{array}{l}130 \text { in-service teachers with technological } \\
\text { competence from a local Cyprus } \\
\text { university }\end{array}$ & $\begin{array}{l}\text { INTERACT: an online professional } \\
\text { development platform aiming to improving } \\
\text { teachers' intercultural competence in the } \\
\text { Cypriot context. }\end{array}$ \\
\hline Leh, Grau, \& Guiseppe & 2015 & $\begin{array}{l}10 \text { pre-service teachers from a } \\
\text { northeastern university in U.S.A. and } 26 \\
\text { from a southern Germany university. }\end{array}$ & $\begin{array}{l}\text { An online intercultural exchange project } \\
\text { embedded with an ensuing face-to-face } \\
\text { meeting. }\end{array}$ \\
\hline McCalman & 2014 & $\begin{array}{l}20 \mathrm{~K}-12 \text { teachers who were pursuing } \\
\text { English as a Second Language (ESL) } \\
\text { certification in a U.S.A. state university. }\end{array}$ & $\begin{array}{l}\text { A pilot study exploring teachers' } \\
\text { expectations about the effect of an online } \\
\text { course on their teaching and classroom } \\
\text { environment, their experiences pertaining } \\
\text { to the course and their perceptions } \\
\text { regarding the learned intercultural } \\
\text { communicative competence on their } \\
\text { working and own lives. }\end{array}$ \\
\hline
\end{tabular}

\subsection{Online Projects of Technology Applications}

\section{The first project}

We start with Ferdig et al.'s (2007) five innovative technology applications for multicultural education purpose, amongst which two are highly relevant to the topic of this article. The first application was a teacher education literacy tool named the reading classroom explorer (RCE), which aimed to help pre-service teachers to learn literacy instruction in a hypermedia context. Many database resources such as movies, questions, transcripts were available. Pre-service teachers had the opportunity to be exposed to diverse teaching environments, and had to think and analyse critically about what they observed. Subsequent survey results showed that RCE helped teacher candidates develop a better understanding of student and pedagogical diversity and multicultural issues. Despite RCE's advantages for pre-service literacy teachers, what remained unknown was whether these teachers continued to use RCE in their future jobs or how it influenced their professional lives after graduation. Longitudinal research is warranted to address these issues.

The second technological application, named "International Leadership in Educational Technology" and funded by Europe and U.S.A. created a virtual intercultural learning setting for doctoral candidates who were aiming to become prospective leaders of educational technology (Ferdig et al., 2007, p. 53). The participants consisted of graduate students from three European universities and three U.S.A. universities, with collaboration of faculty and students supported by technology. The "Online Reading Group community" and the "Summer Academy" and continuing "long-term internship" overseas (Ferdig et al., 2007, p. 55), respectively, enabled students to develop an open attitude towards other cultures, form friendships beyond different countries, and cultivate multicultural awareness and competence. However, despite its advantages, there were two issues. Firstly, it was hard for most doctoral candidates to afford the extra expense of overseas internships because of family responsibilities (Ferdig et al., 2007, p. 55). Secondly, the measurements of ICC here could be subjective because 
it was based on students' reports, interviews and the like (Ferdig et al., 2007, p. 55). Ferdig et al. (2007) called on future research to develop technologies that could expedite the attainment of ICC of doctoral students within a shorter period, and at the same time increase their commitment to this online community.

\section{The second project}

The Continuing Intercultural Professional Development in Europe (CIPDE) project, which sought to meet an array of European Commission policy goals, created a virtual learning community to foster intercultural professional development among teachers from five European countries - including the UK, Poland, Netherland, Italy and Finland - from 2007 to 2009 (Carroll, Britton, \& Barr, 2010). This two-year program, essentially a shared professional community of practice, provided e-learning opportunities for teachers at all stages to interact, exchange ideas, engage in critical thinking, and ultimately reflect on own their practice of teaching and intercultural teaching beyond cultural aspects and limitations. It was regarded less as a formal course of systematic learning and more of a process of acquiring intercultural knowledge (Carroll, Britton, \& Barr, 2010). This process involved teachers-as-learners, with them taking part in meaningful activities such as sharing their teaching insights, commenting on others' ideas, and critiquing one's own cultural understanding or teaching. These collaborative activities led to the transference of skills, allowing the participants to apply them to their own pedagogical practice - a reflective and creative process which would eventually influence their students.

As for the impact of CIPDE project, Carroll et al. (2010) found overall, most participants were satisfied with their networked learning experience from this virtual learning environment. Developing cultural awareness, exploring, and challenging their way of thinking, enhancing intercultural learning experiences, and contributing critical insights were some of the gains cited. However, like other online projects, this CIPED project was not issue-free. More specifically, there were perceived technological access barriers, language barriers for non-native teachers, decreased engagement of some teachers due to lack of time, IT problems, limited knowledge, demanding input, perceived sensitive topics or material or lack of guidance, perceived group disharmony, etc. Long-term or sustainable involvement or commitment to the online learning environment seemed to be the most outstanding issue. It remains a question as to how to quantify teachers' intercultural professional development other than through self-reporting methods.

\section{The third project}

The third project, INTERACT, was an online professional development platform aiming to improving teachers' ICC in the Cypriot context (Hajisoteriou et al., 2018). It drew on the theoretical framework of virtual communities of practice (VCoP) (Hajisoteriou et al., 2018). In line with literature, this VCoP entailed sharing, engagement, and collaboration among teachers by means of web technologies. According to Hajisoteriou et al. (2018), the project underwent design and implementation in five phases and they focused on the 4th and 5th phases, which were the implementation (which lasted for one year) and post-implementation (which, time-wise, overlapped with the 4th phase) stages, respectively. 130 in-service teachers with technological competence from a local Cyprus university used this online platform; from this group, 40 were selected for classroom observation. From their findings, three themes were discernible; namely, "collaborative-inquiry research", "family and community mobilisation" and "intercultural online pedagogy" (Hajisoteriou et al., 2018, p. 22).

In "collaborative-inquiry research", participants creatively have an online "critical friend" to challenge their practices; participants also invited other professionals (such as sociologists and psychologists) to work with them on specific topics - for instance, developing intercultural friendship to solve real-situation problems. Through these activities, teachers felt empowered to create new ways of reflecting on and transforming their pedagogies to promote intercultural and inclusive education through collaboration with their colleagues. With respect to "family and community mobilisation", the teachers' online interaction enabled them to reach parents and other members of their community more easily, thereby increasing parental and community involvement to better immerse their students in a more diverse world. "Intercultural online pedagogy" denotes how the teachers were inspired to apply their learning experiences from the online technologies into their regular curriculum and teaching. For instance, they created chatrooms and other similar online platforms and invited their students to share their opinions there. Such utilisation of online pedagogy allows students to communicate with their peers beyond an in-school setting, allowing for a more diverse environment to be explored and enhance the building of intercultural awareness and skills.

The INTERACT project embedded constructivist learning theory, experiential learning (i.e. learning by doing), and affect, cognition and behaviour with technological environment. Drawing from online materials of lectures, PowerPoint presentations, books and papers, teachers band together in their online classrooms to brainstorm and learn, all the while developing mutual trust and respect, ultimately enabling them to change their pedagogies and 
intercultural teaching methods in real-world classrooms. In this sense, this project seemed very successful in enhancing teachers' ICC.

Notwithstanding its achievements, a few questions regarding the project should not be neglected. Firstly, after the one-year implementation period was over, did the teachers continue utilizing this project's platform for self-learning or school teaching practice? Secondly, as self-reporting - which is understood to be subjective was used as a measure in this project; a more quantifiable evaluation of the teachers' improved ICC level was unavailable. Thirdly, as the participants are in-service teachers and technological competent, would it generate different findings if pre-service teachers and those who are less competent with IT participate in the project? Last but not least, the generalisability of this project is as yet unknown, as it was not carried out in a large scale or beyond the country of Cyprus.

\section{The fourth project}

The fourth project by Leh, Grau, and Guiseppe (2015) investigated the effects of an online intercultural exchange project among pre-service teachers in two countries - U.S.A. and Germany. German students were first split up into 10 groups. 10 students from U.S.A. then joined them, with one U.S.A. student in each group. The students worked together outside class to deliberate the importance of diversity in education through various telecommunication methods (for example, Skype, Facebook, and text). The two groups subsequently met in-person a fortnight later to discuss their findings. All participants filled out surveys before and after the face-to-face group meeting, and completed written reflective essays to evaluate "cultural preconceptions, the effectiveness of the project methods and feelings towards the use of technology to facilitate multi-cultural connections" (Leh \& al., 2015, p. 102). The findings indicated that the prior online intercultural exchange had decreased barriers typically present at first-time meetings, and consequently led to a higher sense of camaraderie between the participants during their face-to-face meeting; additionally, the students expressed a deeper understanding of cultural diversity in education (Leh \& al., 2015). This process also successfully facilitated an increase in the students' intercultural communication competence. One major limitation of this study was the time frame of online intercultural exchange and face-to-face interactions, limiting the applicability of these findings to other populations.

\section{The fifth project}

The last project is a pilot study in which K-12 teachers, who were pursuing English as a Second Language (ESL) certification in a U.S.A. state university, participated in an online intercultural course. The study's aim was to explore the teachers' expectations about the effect of this online course on their teaching and classroom environment, their experiences pertaining to the course and their perceptions regarding the learned intercultural communicative competence on their working and own lives (McCalman, 2014).

Over a period of three semesters, data from 20 randomly selected ESL female participants was collected from their comments on the Blackboard platform. The Discussion Board on Blackboard functioned as a professional community of practice, providing the student-teachers the opportunity to exchange views and experiences, and share understanding and learning. The data revealed the teachers' positive expectations about the training course's influence on their working and personal lives, and of increased intercultural awareness and sensitivity. Their determination to transfer and apply new knowledge and skills into teaching, and open and emphatic attitudes to student diversity was made apparent as well. Overall, the results indicated that the teachers appeared ready and positive to apply ICC in their pedagogy, but were less confident about interacting with ESL learners' parents due to language barriers. It suggested that the most ideal teaching method for foreign students in this course, as highlighted by the participants, was the mixed mode of half online and half face-to-face communications methods such as Skype interactions. It could be inferred that even with advantages of online CoP learning, face-to-face communication was still essential. It is possible that the teachers were more comfortable asking cultural or sensitive questions via the traditional mode, or learning in a way which cannot be replicated by the online mode.

One limitation of this pilot study is that its results cannot be generalised due to the small sample size, which consisted of female participants only likely due to the fact that there are more female than male ESL teachers (McCalman, 2014). Different results may be obtained with male teachers or with those who are not seeking ESL certification. 


\section{Discussion}

\subsection{The Nature of Online Learning of ICC in Virtual CoP}

The abovementioned projects reflect the constructivism theory of learning for teacher-as-learners (Hajisoteriou et al., 2018; White-Clark, Robertson, \& Lovett, 2017), problem-solving-based learning, situated learning, and experiential learning. Teachers are encouraged to construct active collaborative learning, share knowledge and experience, negotiate contradictory views, apply and transfer knowledge, think critically, and solve problems in a shared virtual CoP. Reflecting on their learning and teaching practice also supports teachers' metacognitive development in building and employing ICC knowledge and skills. Such a constructive approach helps them engage in meaningful learning - as long as time is taken to make sense of what they have picked up, and relate it to their existing knowledge. Online learning is also about affect, behaviour and cognition in learning with technology. During the learning process, teachers may feel that it is convenient, enjoyable, motivating, engaging and are satisfied with the outcomes. Conversely, they are also likely to feel anxious, frustrated or discouraged. They access digital learning content and construct online communication and cooperation on tasks or solving problems in virtual CoP. Regarding the cognition, they reflect on understanding, critical thinking and analysis, decision-making and planning etc.

\subsection{Issues Related to the Virtual CoP}

Compared with traditional modes of face-to-face intercultural training like workshops, seminars or conferences, online training has more advantages in terms of flexibility pace, location boundaries, affordability, anonymity (Carroll \& Barr, 2010; Hajisoteriou et al., 2018; McCloskey, 2012), improving digital competence, opportunities to interact with colleagues from other cultures and countries, more varied resources, the speed of peer discussion and feedback (Carroll \& Barr, 2010; McCloskey, 2012), collective learning and reciprocity (Hew \& Hara, 2007), and time for reflection (McCloskey, 2012). Yet, some drawbacks merit attention. These include (but are not limited to) teachers' lack of time, discomfort with technology, lack of accessibility to the necessary IT tools, language barriers for non-native speakers, input required, constrained communication, decreased motivation and unsustainable commitment and engagement (Carroll \& Barr, 2010), poor technological knowledge (White-Clark et al., 2017), and the absence of non-verbal cues leading to misinterpretation and group disharmony (Hew \& Hara, 2007). Some teachers misuse online platforms by complaining about work instead of seeking serious learning opportunities (Hew \& Hara, 2007). Another potential drawback is the complexity in responding to teachers while taking into account variance in their ICC levels and different professional development needs (Dejaeghere \& Cao, 2009).

\section{Conclusion and Implications}

In this era of globalisation, multi-education and cultural diversity is evident at all levels of education, from primary schools to universities. Students have no choice but to acquire the skills of 21 st century in order to function and succeed in the global society (Gopal, 2011; Schlein, 2018). As a sign of the times, the Program for International Student Assessment (Pisa) conducted by the Organisation for Economic Cooperation and Development (OECD), even included the domain of global competence in their 2018 test. (https://www.oecd.org/pisa/pisa-2018-global-competence.htm)

In this respect, it would not be inaccurate to say that, on a moral and professional basis, teachers should be obligated to impart such intercultural knowledge and skills to their students. However, to do so, they would need to be adequately equipped - through thorough and rigorous training - before they are able to respond to their students' needs at a level which would truly allow them to develop and reach their full potential. Only when teachers become an agent of change, can they be more likely to transform the school climate into a more inclusive environment (Sales, Traver, \& García, 2011). Without intercultural professional training, teachers are likely to feel frustrated, unsupported, isolated, unprepared, and incompetent to teach in classroom (Gopal, 2011; Hajisoteriou et al., 2018). This article has illustrated the impetus for teachers' ICC learning and training to occupy a prominent niche in the school agenda.

Drawing parallels with other industries wherein a tsunami of technological advancements has dramatically improved the performance, development and delivery of entire chains and networks - and most importantly, the ability to acquire fuller cognisance of cultures beyond one's own - in the education industry is, on the whole, not possible at the present moment. This is because despite the valuable and propitious prospects for teachers' intercultural professional development that networked technologies in online virtual community or other technology-backed means have opened up, these promising affordances have yet to be fully explored and leveraged upon. For instance, in the projects covered, none were longitudinal research that were conducted to measure the effectiveness of a virtual online project on the ICC level of teachers, with quantifiable 
measurements. There was also no evidence of a long-term or large-scale project which attempted a blend of both face-to-face and networked training, which (Hew \& Hara, 2007; McCalman, 2014) noted could be adopted in a contextualised way to cater to different professional development needs of teachers.

More online projects are clearly needed, as the industry's understanding of the extent to which these technologies can be harnessed to facilitate the broadening of educators' horizons is clearly inadequate. While the availability and quantity of such projects is lacking, this is but one area to be considered; the quality and sustainability of the said projects (in particular those built with a view for long term use) as well as their inclusivity all need to be taken into consideration as well. To attain a level of change that has brought positive changes to all sectors in other industries, future technology research must address the aforementioned issues to ensure that technology maximally facilitates instead of thwarting the objectives of ICC (McCloskey, 2012).

\section{References}

Carroll, M., Britton, A., \& Barr, I. (2010). Intercultural Professional Development within a Virtual Learning Community. Citizenship, Social and Economics Education, 9(2), 129-143. https://doi.org/10.2304/csee.2010.9.2.129

Copur-Gencturk, Y., Cimpian, J. R., Lubienski, S. T., \& Thacker, I. (2020). Teachers' Bias Against the Mathematical Ability of Female, Black, and Hispanic Students. Educational Researcher, 49(1), 30-43. https://doi.org/10.3102/0013189X19890577

Davis, N., Cho, M. O., \& Hagenson, L. (2005). Editorial: Intercultural Competence and the Role of Technology in Teacher Education. Contemporary Issues in Technology and Teacher Education, 4(4), 384-394. Norfolk, VA: Society for Information Technology \& Teacher Education.

Deardorff, D. K. (2009). The Sage Handbook of Intercultural Competence. Thousand Oakes, CA: Sage Publication, Inc.

Dejaeghere, J. G., \& Cao, Y. (2009). Developing U.S. teachers' intercultural competence: Does professional development matter? International Journal of Intercultural Relations, 33(5), 437-447. https://doi.org/10.1016/j.ijintrel.2009.06.004

Dervin, F. (2014). International pre-service teachers' perceptions of experienced teachers' intercultural (in)competenssce in Finland. Educational Practice and Theory, 36(2), 5-25. https://doi.org/10.7459/ept/36.2.02

Ferdig, R. E., Coutts, J., Dipietro, J., Lok, B., \& Davis, N. (2007). Innovative technologies for multicultural education needs. Multicultural Education \& Technology Journal, 1(1), 47-63. https://doi.org/10.1108/17504970710745201

Fungchomchoei, S., \& Kardkarnklai, U. M. (2016). Exploring the Intercultural Competence of Thai Secondary Education Teachers and its Implications in English Language Teaching. Procedia - Social and Behavioral Sciences, 236, 240-247. https://doi.org/10.1016/j.sbspro.2016.12.017

Gopal, A. (2011). Internationalization of Higher Education: Preparing Faculty to Teach Cross-culturally. International Journal of Teaching and Learning in Higher Education, 23(3), 373-381.

Gutiérrez Esteban, P., Alonso Díaz, L., Smyrnova-Trybulska, E., Capay, M., Ogrodzka-Mazur, E., Pinto, P. J. G., \& Yakovleva, O. (2015). Intercultural and digital competence in teacher training from an international perspective: Poland, Portugal, Slovakia, Spain and Russia. RELATEC: Revista Latinoamericana de Tecnología Educativa, 14(1), 145-157.

Habib, Z. (2018). International Mindedness and Intercultural Competence: Perceptions of Pakistani Higher Education Faculty. Journal of Education and Educational Development, 5(1), 60. https://doi.org/10.22555/joeed.v5i1.1807

Hajisoteriou, C., Karousiou, C., \& Angelides, P. (2018). INTERACT: building a virtual community of practice to enhance teachers' intercultural professional development. Educational Media International, 55(1), 15-33. https://doi.org/10.1080/09523987.2018.1439709

Han, X., \& Song, L. (2011). Teacher cognition of intercultural communicative competence in the Chinese ELT context. Intercultural Communication Studies, 20(1), 175-192.

Hew, K. F., \& Hara, N. (2007). Empirical study of motivators and barriers of teacher online knowledge sharing. Education Technology Research Development, 55(6), 573-595. https://doi.org/10.1007/s11423-007-9049-2 
Jiang, Q., Yuen, M., \& Horta, H. (2020). Factors Influencing Life Satisfaction of International Students in Mainland China. International Journal for the Advancement of Counselling. https://doi.org/10.1007/s10447-020-09409-7

Lee, T., \& Lim, D. H. (2017). International Faculty Development in U.S. Higher Education. In K. Jared (Ed.), Handbook of Research on Promoting Cross-Cultural Competence and Social Justice in Teacher Education (pp. 304-319). Hershey, PA, USA: IGI Global. https://doi.org/10.4018/978-1-5225-0897-7.ch016

Leh, J. M., Grau, M., \& Guiseppe, J. A. (2015). Navigating the development of pre-service teachers' intercultural competence and understanding of diversity: The benefits of facilitating online intercultural exchange. Journal for Multicultural Education, 9(2), 98-110. https://doi.org/10.1108/JME-12-2014-0042

Wanrong, Lei. (2021). A Survey on Preservice English Teachers' Intercultural Communicative Competence in China. English Language Teaching, 14(1), 37-47. https://doi.org/10.5539/elt.v14n1p37

Manzoor, A. (2016). Promoting Effective Learning in Diverse Classrooms. In S. Brent \& P. Amiram (Eds.), Global Perspectives on Contemporary Marketing Education (pp. 229-244). Hershey, PA, USA: IGI Global. https://doi.org/10.4018/978-1-4666-9784-3.ch014

Marta Garrote, S., \& María Fernández, A. (2016). Intercultural Competence in Teaching: Defining the Intercultural Profile of Student Teachers. Bellaterra Journal of Teaching \& Learning Language \& Literature, 9(4), 41-58. https://doi.org/10.5565/rev/jt13.670

McCalman, C. L. (2014). International Instructor Preparing Teachers for Multicultural Classrooms in the United States: Teaching Intercultural Communication Competence Online. New Directions for Teaching and Learning, 2014(138), 73-81. https://doi.org/10.1002/tt.20098

McCloskey, E. (2012). Global Teachers: A Model for Building Teachers' Intercultural Competence Online. Comunicar, 19(38), 41-49. https://doi.org/10.3916/C38-2012-02-04

Mede, E., \& Cansever, Z. M. (2017). Integrating Culture in Language Preparatory Programs: From the Perspectives of Native and Non-native English Instructors in Turkey. In J. Kathryn \& R. M. Jason (Eds.), Intercultural Responsiveness in the Second Language Learning Classroom (pp. 16-35). Hershey, PA, USA: IGI Global. https://doi.org/10.4018/978-1-5225-2069-6.ch002

Nawaz, T. (2018). Internationalisation strategy, faculty response and academic preparedness for transnational teaching: The significance of pre-departure training. Education \& Training (London), 60(9), 1084-1096. https://doi.org/10.1108/ET-09-2017-0141

Polat, S., \& Ogay, T. (2014). Preservice Teachers' Intercultural Competence: A Comparative Study of Teachers in Switzerland and Turkey. Eurasian Journal of Educational Research, 14, 19-38. https://doi.org/10.14689/ejer.2014.54.2

Ryan, J., \& Hellmundt, S. (2003). Excellence through diversity: Internationalisation of curriculum and pedagogy, paper presented at the 17th IDP international education conference, Oct.

Sales, A., Traver, J. A., \& García, R. (2011). Action research as a school-based strategy in intercultural professional development for teachers. Teaching and Teacher Education, 27(5), 911-919. https://doi.org/10.1016/j.tate.2011.03.002

Schlein, C. (2018). (Un)Learning to Teach Through Intercultural Professional Development. Charlotte, NC: Information Age Publishing.

$\mathrm{Sia}$, E. (2014). Student motivation, intercultural competence and transnational higher education: Uzbekistan, a case study. The Journal of Sscholarship of Teaching and Learning, 15(1), 57-69. https://doi.org/10.14434/josotl.v15i1.13000

Smith, K. (2009). Transnational teaching experiences: an under-explored territory for transformative professional development. International Journal for Academic Development, 14(2), 111-122. https://doi.org/10.1080/13601440902969975

Villegas-Reimers, E. (2003). Teacher professional development: An international review of the literature. París: International Institute for Educational Planning.

White-Clark, R., Robertson, S., \& Lovett, A. (2017). Using Technology to Bridge the Intercultural Gap in the Classrooms of K-8 ENL Students. In Jones, K. \& Mixon, J. R. (Eds.), Intercultural Responsiveness in the Second Language Learning Classroom (pp. 222-237). IGI Global. https://doi.org/10.4018/978-1-5225-2069-6.ch013

\section{Copyrights}

Copyright for this article is retained by the author(s), with first publication rights granted to the journal.

This is an open-access article distributed under the terms and conditions of the Creative Commons Attribution license (http://creativecommons.org/licenses/by/4.0/). 